\title{
Long non-coding RNAs as novel biomarkers for breast cancer invasion and metastasis (Review)
}

\author{
KAIJIONG ZHANG ${ }^{1}$, ZHENGLIAN LUO ${ }^{1}$, YI ZHANG ${ }^{1}$, XIAOYU SONG ${ }^{2}$, \\ LI ZHANG $^{2}$, LICHUN WU ${ }^{2}$ and JINBO LIU ${ }^{1}$ \\ ${ }^{1}$ Department of Laboratory Medicine, The Affiliated Hospital of Southwest Medical University, Luzhou, Sichuan 646000; \\ ${ }^{2}$ Department of Laboratory Medicine, Sichuan Cancer Hospital, Chengdu, Sichuan 610041, P.R. China
}

Received November 20, 2015; Accepted April 26, 2017

DOI: $10.3892 / 01.2017 .6462$

\begin{abstract}
Breast cancer (BC) is now the most common malignancy worldwide, with high prevalence and lethality among women. Invasion and metastasis are the major reasons for breast cancer-associated mortality. However, the underlying mechanism of invasion and metastasis has not been entirely elucidated. Long non-coding RNAs (lncRNAs) are a large class of non-coding transcripts that are $>200$ bases in length and cannot encode proteins. Evidence has indicated that lncRNAs regulate gene expression at the levels of epigenetic modification, transcription and post-transcription. In addition, they are involved in diverse tumor biological processes, including cell proliferation, apoptosis, invasion, metastasis and angiogenesis. The present review focuses on the recent progress of lncRNAs in breast cancer invasion and metastasis, aiming to provide novel strategies for the clinical prevention, diagnosis and treatment of breast cancer.
\end{abstract}

\section{Contents}

1. Introduction

2. Mechanisms of invasion and metastasis in breast cancer

3. Roles of invasion and metastasis-associated lncRNAs in breast cancer

4. Conclusions

\section{Introduction}

Breast cancer is the most frequently diagnosed cancer and the leading cause of cancer-associated mortality among women worldwide, with an estimated 1.7 million cases and

Correspondence to: Professor Jinbo Liu, Department of Laboratory Medicine, The Affiliated Hospital of Southwest Medical University, 25 Taiping Street, Luzhou, Sichuan 646000, P.R. China E-mail: liujb7203@163.com

Key words: breast cancer, long non-coding RNAs, invasion, metastasis
521,900 mortalities in 2012 , which accounts for $25 \%$ of all cancer cases and $15 \%$ of all cancer-associated mortalities among females (1). With the development of society and the economy, the incidence of breast cancer is increasing rapidly, particularly in the less developed countries of the world (1). Although advances have been made in the treatment of breast cancer over the previous decades, the prognosis for patients remains poor due to the high rate of metastasis $(1,2)$. Metastasis is the primary cause of relapse and mortality of patients with breast cancer (3-5). Once metastasis occurs, the 5-year survival rate is $<25 \%$ (6). Therefore, there is an urgent requirement to identify novel molecular biomarkers of metastasis, which may be useful in the early diagnosis, prognosis assessment and prediction of response to therapy for breast cancer.

Metastasis is a multifactorial and multistep process, which is regulated by the abnormal expression of various genes, including snail family zinc finger (Snail1 and Snail2), zinc finger E-box binding homeobox (ZEB1 and ZEB2), twist basic helix-loop-helix transcription factor 1 (Twist1) and matrix metalloproteinases (MMPs) (7). In previous years, although numerous studies (7-9) have focused on the identification and characterization of the genes and gene products that drive a metastatic process, the precise molecular mechanism that governs the process has been largely unknown. The identification of non-coding RNAs (ncRNAs) has opened a novel avenue for studies on cancer metastasis. It has been reported that only $\sim 2 \%$ of the human genome encodes protein-coding genes, and at least $70 \%$ of the human genome is actively transcribed, generating a vast range of ncRNAs $(10,11)$. Although these ncRNAs were previously regarded as transcriptional 'noise', it has become clear that ncRNAs perform a crucial role in cellular development and tumor progression, including metastasis $(12,13)$. Based on transcript size, ncRNAs are classified into two major groups. Transcripts shorter than 200 nucleotides (nts) are referred to as small ncRNAs, such as microRNAs (miRNAs/miRs) (14), which have been well established to extensively affect cancer invasion and metastasis $(15,16)$. The other group is composed of long non-coding RNAs (lncRNAs), which are pervasively transcribed in the genome and exhibit emerging roles in tumorigenesis (17-20).

lncRNAs are a group of RNA molecules, which are $>200$ nts in length, lack functional open reading frames (ORFs) and cannot encode proteins; they regulate gene expression 
at the epigenetic, transcriptional and post-transcriptional levels $(21,22)$. The majority of lncRNAs are located in the cytoplasm (23-25), and are transcribed by RNA polymerase II, spliced and polyadenylated $(20,26)$. IncRNAs can be classified into five general categories according to their location relative to nearby protein-coding genes: Sense lncRNA, antisense lncRNA, bidirectional lncRNA, intronic lncRNA and intergenic lncRNA $(27,28)$. Although thousands of IncRNAs have been identified to be involved in numerous physiological and pathological processes, including cellular metabolism, differentiation, proliferation and apoptosis (29-31), the precise mechanisms by which lncRNAs function remain poorly understood. An ever-growing amount of lncRNAs identified have essential roles in regulating oncogenic processes, such as metastasis, and their mechanisms require additional investigation to be fully understood.

\section{Mechanisms of invasion and metastasis in breast cancer}

Metastatic breast cancer frequently represents an incurable impasse and a poor prognosis for patients. Subsequent to receiving diagnosis, the mechanisms involved in metastasis are largely unknown (32). Metastasis is a complex succession of cell-biological events, collectively termed the invasion-metastasis cascade, which involves multiple factors and steps: Cancer cells break away from primary tumors, invade locally through surrounding extracellular matrix and stromal cell layers, intravasate into the circulation of blood or lymphatic vessels, survive within the vasculature, extravasate into distant tissues, and reinitiate proliferation and growth programs of tumors at metastatic sites (7). These complex cell-biological processes are coordinated by the expression of various genes and the regulation of signaling cascades, which confer the ability of incipient metastatic tumor cells to successfully generate high-grade, life-threatening malignancies $(7,33)$.

Epithelial-mesenchymal transition (EMT) and its reverse process, mesenchymal-epithelial transition (MET), are essential for cancer metastasis and distal colonization $(34,35)$. EMT is typically believed to be the first step of the invasion-metastasis cascade, and the significance of EMT for breast cancer invasion and metastasis has been shown in a large number of in vitro and in vivo studies (36-38). The most critical and well-studied EMT-associated molecule is the epithelial adhesion molecule, E-cadherin $(39,40)$. In EMT, the expression of E-cadherin is decreased, while the expression of mesenchymal markers such as $\mathrm{N}$-cadherin, vimentin or fibronectin is increased, and this switch promotes the capacity of cancer cell invasion and mobility $(41,42)$. A decrease in E-cadherin expression is considered to be a fundamental event of EMT, and is prominently associated with breast cancer invasion and metastasis (43-45). The decrease in E-cadherin leads to inactivation of glycogen synthase kinase $3 \beta$ through phosphorylation, thus stabilizing the released $\beta$-catenin, which results in the induction of wide-ranging transcriptional and functional changes, thereby promoting breast cancer cell metastatic dissemination (46). Notably, the expression of E-cadherin will be re-established in cells that come from metastatic tumor colonies (47). Once cancer cells disseminate to a secondary organ, the process of MET may occur, and the levels of E-cadherin will be increased in these cells compared with the cells from the primary tumor (48). Furthermore, Snail1, Snail2, ZEB1, ZEB2 and Twist1 have all been shown to be important master factors of EMT $(49,50)$. A typical example illustrated that Snail1 represses expression of epithelial genes by binding to E-box DNA sequences in the proximal promoter region of E-cadherin, which recruits the polycomb repressive complex 2 (PRC2), resulting in methylation and acetylation at histone $\mathrm{H} 3$ lysine (H3K)4, H3K9 and $\mathrm{H} 3 \mathrm{~K} 27$, and thereby silencing the expression of E-cadherin and initiating EMT-relevant processes to promote cancer metastasis (51-55).

Several signaling pathways have also been reported to be involved in EMT and metastasis, including the transforming growth factor (TGF)- $\beta$, Wnt $/ \beta$-catenin, Hedgehog, phosphoinositide 3-kinase (PI3K)/AKT and nuclear factor (NF)- $\kappa$ B pathways (56-60). These pathways contribute to the activation of downstream transcriptional targets and ultimately initiate the program of cell adhesion, migration and metastasis. In addition to transcription factors of EMT, the invasion-metastasis cascade is also regulated by post-transcriptional regulatory networks, including lncRNAs and miRNAs $(61,62)$. A previous study demonstrated that miRNAs exert their effects at multiple steps in the metastatic cascade by effecting cancer cell adherence, migration, invasion, motility and angiogenesis (63). However, the molecular mechanisms driving breast cancer invasion and metastasis have been scant, as lncRNAs have only recently been identified. The extent to which lncRNAs specifically facilitate metastasis remains unknown. This review focuses on individual lncRNAs involved in breast cancer metastasis, and investigates the mechanisms and functions of several known lncRNAs that have only recently been identified. This may provide valuable targets for potential clinical applications of breast cancer in early diagnosis and management.

\section{Roles of invasion and metastasis-associated IncRNAs in breast cancer}

HOX antisense intergenic RNA (HOTAIR). HOTAIR, a 2158-nt ncRNA located on chromosome 12q13.13, was identified in 2007 (64). HOTAIR expression is increased in primary and metastatic breast cancer, and its expression level in primary tumors is a powerful predictor of eventual metastasis and mortality (65). Overexpression of HOTAIR in breast cancer cells induced genome-wide retargeting of PRC2, leading to trimethylation of H3K27 (H3K27me3), gene expression, and increased cancer invasiveness and metastasis (65). Enhancer of zeste homolog 2 (EZH2), a subunit of PRC2, is highly expressed in breast cancer, and the levels of EZH2 have been found to be strongly associated with breast cancer invasion and metastasis (66). HOTAIR and EZH2 expression levels are highly associated; co-expression of HOTAIR and EZH2 are associated with a worse clinical outcome (67).

HOTAIR serves as a key regulator in controlling the multiple signaling mechanisms involved in EMT and stemness establishment; it promotes the repression of E-cadherin by PRC2, and silencing the expression of HOTAIR can prevent EMT induction and cancer stem cells arising (68). A subsequent study revealed that HOTAIR functions as a competing endogenous RNA to regulate EMT and the invasive program by competing for miR-7; the decrease in miR-7 promotes EMT of breast cancer stem cells by activating the signal transducer 
and activator of transcription 3 (STAT3) pathway, and that inhibits the expression of HOTAIR, which may serve as a good strategy for treating highly invasive breast cancer (69). In metastatic breast cancer, HOTAIR also inhibits miR-568 to maintain the expression of nuclear factor of activated T cells 5 , which promotes EMT and metastasis of breast cancer cells by transcriptionally activating calcium-binding protein S100A4 and vascular endothelial growth factor C (70).

HOTAIR is also significantly associated with estrogen receptor (ER) (71,72). The promoter ofHOTAIR contains multiple functional estrogen response elements, and is transcriptionally induced by estradiol (E2) (73). ER and various ER coregulators, including histone methylases such as mixed-lineage leukemia (MLL)1 and MLL3, and CREB-binding protein/p300, bind to the promoter of HOTAIR in an E2-dependent manner $(73,74)$. Knockdown of ER and MLLs can decrease E2-induced HOTAIR expression (73). HOTAIR overexpression may serve as an independent biomarker for the prediction of the risk of metastasis in patients with ER-positive breast cancer (72). Recently, Tao et al (75) demonstrated that estrogen promoted HOTAIR through G protein-coupled estrogen receptor 1-mediated miR-148a inhibition, and that estrogen-induced breast cancer cell migration was reversed by silencing HOTAIR in triple-negative breast cancer.

H19. H19 was the first IncRNA identified in 1991 (76); it is derived from a large imprinted locus on human chromosome $11 \mathrm{p} 15.5$, and performs a crucial role in genomic imprinting during growth and development (77). H19 is transcribed by RNA polymerase II, spliced and polyadenylated in the cytosol (78), and is largely or exclusively expressed from the maternal allele (79). Although $\mathrm{H} 19$ has been demonstrated to be involved in diverse biological processes of multiple numbers of tumors, there remains considerable debate about its roles. It has been reported that $\mathrm{H} 19$ serves as a tumor suppressor in Wilm's tumors, embryonic rhabdomyosarcoma and Beckwith-Wiedemann syndrome (80), while it functions as an oncogene in pancreatic (81), bladder (82), colorectal (83) and gastric (84) cancer. In breast cancer, H19 is proposed to function as an oncogene to potentiate the properties of tumorigenesis (85). H19 promotes breast cancer cell proliferation and invasion by hepatocyte growth factor and E2F transcription factor $1(86,87)$. Matouk et al (88) indicated that H19 was highly expressed in all common metastatic sites regardless of tumor primary origin, and that its expression level was significantly associated with the metastatic potential of breast cancer cells. The overexpression of H19 abolished E-cadherin expression and increased $\mathrm{N}$-cadherin and Slug expression through a mechanism that involves miR-675. Slug could also serve as a positive feedback loop to upregulate H19 expression and activate its promoter (88). In addition, TGF- $\beta$-induced EMT and H19/miR-675 expression level is associated with the PI3K/AKT pathway (89). Recently, Vennin et al (90) demonstrated that $\mathrm{H} 19$ could decrease ubiquitin ligase E3 family (c-Cbl and Cbl-b) expression through its miR-675 directly binding $\mathrm{c}-\mathrm{Cbl}$ and $\mathrm{Cbl}-\mathrm{b}$, which increases the stability and the activation of epidermal growth factor receptor and c-Met, leading to sustained activation of their downstream AKT and ERK signaling pathways, thereby enhancing breast cancer cell proliferation, migration, tumor growth and metastasis.
Metastasis-associated lung adenocarcinoma transcript-1 (MALAT-1).MALAT-1, also termed nuclear-enriched abundant transcript 2, is a highly conserved lncRNA that is $\sim 8,000 \mathrm{nts}$ in length, which was identified in non-small cell lung cancer as a prognostic marker of distant metastasis (91). A number of studies have found that MALAT-1 is extensively dysregulated in several types of human malignant tumors, including lung cancer (91), pancreatic cancer (92), hepatocellular carcinoma (93), cervical cancer (94), colorectal cancer (95), bladder cancer (96) and breast cancer (97). MALAT-1 enhances the potential transcription of EMT and regulates tumor cell proliferation, migration, invasion and metastasis $(98,99)$. MALAT-1 was markedly increased in breast cancer cells compared with in non-cancerous cell lines (97). High concentration E2 treatment causes transcriptional inhibition of MALAT-1 RNA, thus inhibiting the proliferation, migration and invasion of breast cancer cells (97). However, by constrast, $\mathrm{Xu}$ et al (100) revealed that MALAT-1 expression was decreased in breast cancer cell lines and tumor tissue. Lower expression of MALAT-1 was associated with axillary lymph node metastasis and clinical disease progression. knockdown of MALAT1 in breast cancer cell lines induced an EMT program by activating the PI3K/AKT pathway, thereby promoting breast cancer cell migration and invasion (100).

Long stress-induced non-coding transcript 5 (LSINCT5). LSINCT5 is a $2.6-\mathrm{kb}$ transcript that is polyadenylated and transcribed on the negative strand. LSINCT5 is localized in the nucleus and potentially transcribed by RNA polymerase III $(101)$. Studies by Silva et al $(101,102)$ demonstrated that LSINCT5 is greatly overexpressed in breast cancer cell lines and tumor tissues, and its expression is associated with cellular proliferation. In addition, LSINCT5 is also involved in breast cancer invasion and metastasis. Knocking down the expression of LSINCT5 leads to decreased expression of CXC chemokine receptor 4 (CXCR4), a crucial breast cancer marker associated with invasion and metastasis (103). The decrease in CXCR4 will cause a decrease in MMP-9 expression and reversion of EMT, thereby enhancing apoptosis and reducing the incidence of tumor invasion and metastasis (103-105).

Long intergenic non-protein coding RNA-regulator of reprogramming (lincRNA-ROR). lincRNA-ROR is a large intergenic non-coding RNA $\sim 2,600 \mathrm{nts}$ in length that modulates reprogramming (106). lincRNA-ROR was first discovered in induced pluripotent stem cells (iPSCs), and it was reported to serve a vital role in promoting survival in iPSCs and embryonic stem cells, possibly by preventing the activation of cellular stress pathways, including the p53 response (106). lincRNA-ROR suppresses p53 translation through direct interaction with the heterogeneous nuclear ribonucleoprotein (hnRNP) I, and inhibits p53-mediated cell cycle arrest and apoptosis (107). lincRNA-ROR expression is controlled by a key cytoprotective transcription factor, nuclear factor-erythroid 2-related factor (NRF2), in mammary stem cells. NRF2 directly binds the ROR promoter at NRF2 response elements and subsequently inhibits lincRNA-ROR transcriptional activity (108). In addition to transcriptional silencing, knockdown of NRF2 leads to a significant decrease in EZH2 binding and in the repressive marker $\mathrm{H} 3 \mathrm{~K} 27 \mathrm{me} 3$, 
which is associated with increased lincRNA-ROR expression, resulting in mammary stem cell self-renewal (108).

lincRNA-ROR is also associated with miRNAs and may function as a competing endogenous RNA for specific miRNAs to interfere in their function. Wang et al (109) demonstrated that lincRNA-ROR is enriched in the cytoplasm and functions as a molecular sponge for miRNA-145 to upregulate its target genes, including octamer-binding transcription factor 4, sex-determining region Y-box (Sox)2, Kruppel-like factor 4 and Nanog expression. These genes are crucial for stem cell characteristics and the EMT program (110-112). Eades et al (113) identified that lincRNA-ROR is markedly upregulated in triple-negative breast cancer [ER(-), human epidermal growth factor receptor 2(-) and progesterone receptor(-)] and in metastatic disease, and competitive inhibition of miR-145 by lincRNA-ROR results in expression of small GTPase ADP-ribosylation factor 6 (ARF6). ARF6 has an essential role in breast cancer cell invasion (114). The overexpression of ARF6 regulates E-cadherin localization and affects cell-cell adhesion, and then performs an important role in the metastatic process (114-116). Additionally, lincRNA-ROR also competitively binds miRNA-205 to prevent the degradation of miRNA-205 target genes, such as ZEB1 and ZEB2 (116). lincRNA-ROR, as a critical positive regulator of EMT, potentiates breast cancer cell migration and invasion, and promotes the generation of stem cell properties (117). Silencing of lincRNA-ROR will repress breast cancer tumorigenesis and metastasis $(116,117)$.

Translational regulatory lncRNA (treRNA). treRNA (originally termed ncRNA-a7) was identified through genome-wide computational analysis in 2010 and was revealed to function as an enhancer and regulate Snail transcription (118). treRNA consists of two exons and contains three putative ORFs, and its transcript is spliced and polyadenylated. treRNA employs different molecular mechanisms of gene regulation depending on its cellular location. In the nucleus, treRNA acts as an enhancer for neighboring genes such as Snail (118). In the cytoplasm $(\sim 75 \%)$, treRNA functions to downregulate the expression of E-cadherin by suppressing the translation of its mRNA. treRNA reduces the level of E-cadherin protein without affecting the level of its mRNA, but alters the polysome distribution of E-cadherin mRNA. In addition, treRNA promotes the formation of a novel ribonucleoprotein complex with RNA-binding proteins (such as hnRNP K, FMR autosomal homolog (FXR)1, FXR2, poly(U) binding splicing factor 60 and splicing factor $3 \mathrm{~b}$ subunit 3 ). This treRNP complex interacts directly or indirectly with the 3'UTR of E-cadherin mRNA, and reduces the translation efficiency $(119,120)$.

In breast cancer samples, treRNA is significantly upregulated in paired primary and lymph-node metastasis compared with healthy controls. Enforced expression of treRNA significantly promotes breast cancer cell migration and invasion in vitro and tumor lung metastases in vivo, whereas knockdown of treRNA markedly suppresses tumor cellular migration, invasion and metastasis (119). Furthermore, enhanced expression of treRNA could decrease the expression of E-cadherin, zonulaoccludens- 1 and $\beta$-catenin, and increase the expression of fibronectin and vimentin, thus affecting the process of EMT, invasion and metastasis (119). Investigation of the functions of treRNA and RNA-binding proteins may serve as potential diagnostic and prognostic markers, as well as providing therapeutic targets for breast cancer (119).

Brain cytoplasmic RNA 200 (BC200). BC200 is a 200-nt cytoplasmic non-coding RNA that is selectively expressed in the primate nervous system, where it is transcribed by RNA polymerase III (121-123). BC200 is not generally expressed in non-neural organs such as the colon, heart, kidney, liver, spleen or skeletal muscle (122). However, the neuron-specific expression is lost in various human tumors, including breast cancer (123). A previous study revealed that this non-coding RNA is more highly expressed in invasive compared with normal breast tissues or in benign tumors of breast cancer, and its expression in breast cancer cells may serve as a molecular indicator of invasive or potentially invasive malignancy (124). Furthermore, BC200 expression is strongly associated with tumor grade, and it may be used as a prognostic indicator to assess tumor progression $(124,125)$. Therefore, the expression of BC200 may serve as a molecular marker in the diagnosis or prognosis of breast cancer $(124,125)$.

lncRNA-activated by TGF- $\beta$ (lncRNA-ATB). IncRNA-ATB was first identificated in human hepatocellular carcinoma (HCC) cells following TGF- $\beta$ treatment in 2014 (126). The lncRNA is poly(A)-negative, mainly localized in the cytoplasm and has three highly homologous loci on chromosomes 13,14 and $22(126,127)$. High expression of lncRNA-ATB is associated with tumor metastases and a poor prognosis $(128,129)$. Evidence has indicated that IncRNA-ATB promotes HCC cell invasion by competitively binding the miR-200 family, upregulating ZEB1 and ZEB2 mRNA and protein levels, and then inducing EMT and invasion (126). By contrast, depletion of lncRNA-ATB is sufficient to abolish TGF- $\beta$-induced EMT, even though TGF- $\beta$ is known to strongly induce a number of other EMT drivers, including Snail, Slug and Twist (127). In addition, lncRNA-ATB promotes organ colonization of disseminated tumor cells by binding interleukin-11 (IL-11) mRNA, increasing IL-11 mRNA stability, causing autocrine induction of IL-11 and triggering STAT3 signaling (126). IL-11 is a TGF- $\beta$ target gene, the expression of which has been shown to promote bone metastasis of breast cancer (130). lncRNA-ATB has been found to upregulate and induce EMT not only in HCC, but also in colorectal (128) and breast (131) cancer. Shi et al (131) revealed that lncRNA-ATB is markedly upregulated in breast cancer cells and tissues. lncRNA-ATB may promote trastuzumab resistance and the invasion-metastasis cascade by competitively binding miR-200c and upregulating ZEB1 and zinc finger protein 217, thereby inducing EMT (131). Furthermore, the high level of lncRNA-ATB is associated with the trastuzumab resistance of patients with breast cancer (131). Therefore, lncRNA-ATB may serve as a promising biomarker and therapeutic target for breast cancer invasion and metastasis.

Breast cancer anti-estrogen resistance 4 (BCAR4). BCAR4 was identified by functional genetic screening in anti-estrogen resistance human breast cancer cells (132). It was reported to be associated with tumor aggressiveness and tamoxifen resistance $(132,133)$. High BCAR4 mRNA levels may serve as 
an independent predictive factor for poor survival following tamoxifen therapy in breast cancer (133). In addition, elevated BCAR4 expression is associated with ER, PR and ERBB2/3 signaling. Knockdown of ERBB2 or ERBB3 could inhibit cell proliferation $(133,134)$. Recently, novel evidence demonstrated that BCAR4 presents close relevance with breast cancer metastasis and regulates a non-canonical Hedgehog/GLI2 transcriptional program $(135,136)$. BCAR4 provides a driving force in the process of breast cancer progression and metastasis, which is markedly upregulated in breast cancer tissues and cells, and elevated expression of BCAR4 is associated with advanced lymph node metastasis stage and poor survival for patients with breast cancer (135). BCAR4 binds to the domain of unknown function of smad nuclear interacting protein 1 (SNIP1) and releases the inhibitory effect of SNIP1 on the histone acetyltransferase activity of p300, leading to the activation of p300 (135). The activated p300 enhances the acetylation of $\mathrm{H} 3 \mathrm{~K} 18$ on the promoters of GLI2 target transcription units, which releases the inhibitory roles of serine/threonine-protein phosphatase 1 regulatory subunit 10 (PPP1R10, also known as PNUTS) on protein phosphatase 1 enzymatic activity, which consequently modulates RNA Pol II Ser5 phosphorylation levels at GLI2 target gene promoter regions, thus activating the GLI-mediated transcriptional program and promoting cell migration and metastasis $(135,137)$.

HOXA transcript induced by TGF- $\beta$ (HIT). IncRNA-HIT is an uncharacterized lncRNA located in the HOXA gene cluster, which functions in the nucleus and is significantly induced by TGF- $\beta$ (138). Richards et al (138) found that lncRNA-HIT performs an important role in TGF- $\beta$-induced EMT, migration and invasion. Depletion of lncRNA-HIT significantly increases E-cadherin and reduces vimentin in mouse mammary gland epithelial cells, and inhibits TGF- $\beta$ induced migration, invasion and EMT. IncRNA-HIT is also significantly elevated in the highly metastatic mouse mammary tumor cell line (4T1) (138). Knockdown of lncRNA-HIT in this cell line results in significant reduction of cell migration, invasion, tumor growth and lung metastasis (138). Furthermore, lncRNA-HIT is conserved in humans and its expression is associated with more invasive breast cancer progression (138). The expression of IncRNA-HIT could be a potential therapeutic target of breast cancer.

$N F-\kappa B$-interacting lncRNA (NKILA). NKILA, an NF- $\kappa$ Binduced lncRNA, is a 2570-nt intronless transcript that is encoded at chromosome 20q13. NKILA exerts its biological function in the cytoplasm, serves as a negative feedback regulator of $\mathrm{NF}-\kappa \mathrm{B}$ in resting and activated cells, and performs a pivotal inhibitory role in breast cancer progression and metastasis (139). NKILA binds to the NF- $\kappa \mathrm{B} /$ inhibitor of $\mathrm{NF}-\kappa \mathrm{B}(\mathrm{I} \kappa \mathrm{B})$ complex, and inhibits I $\mathrm{B}$ kinase-induced I $\mathrm{B}$ phosphorylation, the NF- $\kappa \mathrm{B}$ pathway and cancer-associated inflammation (139). In addition, NKILA is significantly reduced by miR-103/107-mediated degradation in high-metastatic breast cancer cells, and the decrease of NKILA results in abnormal $\mathrm{NF}-\kappa \mathrm{B}$ activation and thus contributes to cancer metastasis and poor patient outcome (139).

Neuroblastoma-associated transcript 1 (NBAT1). NBAT1 was identified in neuroblastoma as a tumor suppressing lncRNA, and it controls tumor progression by epigenetic silencing of target genes, including Sox9, oncostatin $M$ receptor and versican (140). NBAT1 loss affects neuronal differentiation through activation of the neuronal-specific transcription factor neuron restrictive silencer factor/RE1-silencing transcription factor. Furthermore, loss of NBAT1 is associated with cellular proliferation and invasion (140). NBAT1 regulates tumor biological processes by interacting with PRC2 member EZH2, which suppresses its target gene that affects cell proliferation and migration $(140,141)$. In breast cancer, loss of NBAT1 is also associated with tumor metastasis and poor clinical prognosis (142). Overexpression of NBAT1 could inhibit the migration and invasion of breast cancer cells through EZH2 (142). In addition, NBAT1 could suppress breast cancer metastasis by regulating dickkopf Wnt signaling pathway inhibitor 1 (DKK1) in a PRC2-dependent manner. DKK1 is an inhibitor of the Wnt signaling pathway, which inhibits the migration and invasion of breast cancer (143-145). Mechanically, overexpression of NBAT1 decreases the H3K27me3 level of the DKK1 promoter and activates the expression of DKK1, inhibiting breast cancer cell migration and invasion (146). Therefore, NBAT1 may serve as a breast cancer prognostic biomarker and as a potential therapeutic target to inhibit breast cancer metastasis.

Other IncRNAs. Other IncRNAs have also been found to be involved in breast cancer invasion and metastasis, including steroid receptor RNA activator (SRA), linc00617, LOC554202 and AK058003. SRA was reported to be overexpressed in breast cancer cells; knockdown of SRA in MDA-MB-231 cells reduced the invasiveness and expression of certain critical genes, including thrombospondin 1, caveolin 1, transmembrane protease serine (TMPRSS)2, TMPRSS3, MMP-1 and MMP-9 (147). linc00617 promotes breast cancer cell motility and invasion in vitro and potentiates breast cancer cell metastasis in vivo (148). Furthermore, linc00617 induces the generation of stem cells; it activates the transcription of stemness factor Sox2, which stimulates EMT transition and promotes breast cancer progression and metastasis (148). In addition, LOC554202 (149) and AK058003 (150) were also revealed to be upregulated in breast cancer cells and tissues, and the expression levels of these two lncRNAs were strongly associated with tumor size and advanced clinical stage. Knockdown of Loc554202 and AK058003 significantly inhibits breast cancer cell proliferation, invasion and metastasis $(149,150)$.

\section{Conclusions}

Metastasis is the major cause of breast cancer-associated mortlaity, and the invasion-metastasis cascade of breast cancer is formed from a diverse range of biological processes. Therefore, it is essential to identify how to diagnose breast cancer at the early stage and develop anti-metastatic therapeutics. Emerging evidence is beginning to reveal the potential role of lncRNA in breast cancer pathogenesis, and it is now considered to perform an essential role in pro- and anti-metastatic processes (Table I). These novel findings provide fresh molecular insights into the invasion and metastasis of breast cancer and may suggest a novel strategy for breast cancer 
Table I. Functions of lncRNAs in breast cancer invasion and metastasis.

IncRNA Expression Regulatory mechanisms of invasion and metastasis

HOTAIR Upregulated

Trimethylation of histone $\mathrm{H} 3 \mathrm{~K} 27$ by recruiting PRC2

Repression of E-cadherin by PRC2

Competitively binds miR-7 and miR-568

Transcriptionally induced by estradiol

Induces EMT program and CSCs arising

H19 Upregulated

Induced by HGF and E2F1

Increases EGFR and c-Met

Decreases E-cadherin, increases N-cadherin and Slug

Activates Akt and ERK signaling pathways

MALAT-1 Upregulated

Actives transcription

Regulates expression of cell cycle genes

Regulates EMT program

$\begin{array}{ll}\text { LSINCT5 } & \text { Upregulated } \\ \text { lincRNA-ROR } & \text { Upregulated }\end{array}$

Regulates CXCR4 expression

Suppresses p53 translation

Transcriptionally inhibited by NRF2

Competitively binds miRNA-145 and miRNA-205

Promotes survival of iPSCs and ESCs

treRNA Upregulated

Promotes formation of a ribonucleoprotein complex with

hnRNP K, FXR1, FXR2, PUF60 and SF3B3

Enhances Snail transcription

Decreases expression of E-cadherin, zonulaoccludens- 1 and $\beta$-catenin

Increases fibronectin and vimentin expression

BC200 Upregulated

IncRNA-ATB Upregulated

BCAR4 Upregulated

Sequesters PABP, preventing protein synthesis

Regulates trastuzumab resistance

Competitively binds miR-200c, upregulating ZEB1 and ZNF-217

Induces IL-11 expression

Induced by tamoxifen resistance

Associated with ER, PR and ERBB2/3 signaling

Activation of Hedgehog/GLI2

Activation of p300

lncRNA-HIT Upregulated

Induced by TGF- $\beta$

Decreases E-cadherin and increases vimentin

Regulator of TGF- $\beta$ induced EMT

NKILA Downregulated

Binds to NF- $\kappa \mathrm{B} / \mathrm{I} \kappa \mathrm{B}$ and represses NF- $\kappa \mathrm{B}$ activation

Regulated by miR-103/107

Inhibits the NF- $\mathrm{BB}$ signaling pathway

Inhibits cancer-associated inflammation

NBAT1 Downregulated

Interaction with PRC2 member EZH2

Activation of DKK1 expression

Inhibits the Wnt signaling pathway

SRA Upregulated

Activation of GR, ER $\alpha$, PR and SRAP

Coactivates THBS1, CAV1, TMPRSS2, TMPRSS3, MMP-1 and MMP-9

linc00617 Upregulated

Activates the transcription of stemness factor Sox2

Induces generation of stem cells

AK058003 Upregulated

Regulates $\gamma$-synuclein gene

lncRNA, long non-coding RNA; HOTAIR, HOX antisense intergenic RNA; H3K27, histone H3 lysine 27; miR, microRNA; PRC2, polycomb repressive complex 2; HGF, hepatocyte growth factor; E2F1, E2F transcription factor 1; EGFR, epidermal growth factor receptor; ERK, extracellular signal-regulated kinase; MALAT-1, metastasis-associated lung adenocarcinoma transcript-1; EMT, epithelial-mesenchymal transition; CXCR4, chemokine (C-X-C motif) receptor 4; lincRNA-ROR, long intergenic non-protein coding RNA-regulator of reprogramming; NRF2, nuclear factor-erythroid 2-related factor; iPSC, induced pluripotent stem cell; ESC, endothelial progenitor cell; treRNA, translational regulatory lncRNA; hnRNP K, heterogeneous nuclear ribonucleoprotein K; FXR, FMR autosomal homolog; PUF60, poly(U) binding splicing factor 60; SF3B3, splicing factor 3b subunit 3; PABP, polyadenylate-binding protein; TGF- $\beta$, transforming growth factor- $\beta$; IncRNA-ATB, IncRNA-activated by TGF- $\beta$; ZEB1, zinc finger E-box binding homeobox 1 ; ZNF-217, zinc finger protein 217 ; IL-11, interleukin-11; ER, estrogen receptor; PR, progesterone receptor; ERBB2/3, erb-b2 receptor tyrosine kinase 2/3; BCAR4, breast cancer anti-estrogen

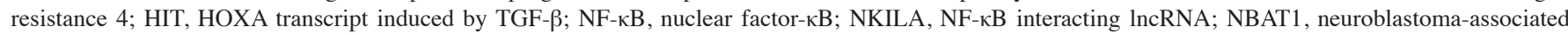
transcript 1; EZH2, enhancer of zeste homolog 2; DKK1, dickkopf Wnt signaling pathway inhibitor 1; GR, glucocorticoid receptor; SRAP, steroid receptor activator protein; THBS1, thrombospondin 1; CAV1, caveolin 1; TMPRSS2/3, transmembrane protease, serine 2/3; MMP-1/9, matrix metalloproteinase-1/9; Sox2, sex-determining region Y-box 2 . 
therapy. However, studies of IncRNAs remain in the early stages, and the underlying mechanism of lncRNAs in regulating the invasion and metastasis of breast cancer is not clear. Furthermore, the expression of lncRNAs in breast cancer lacks specificity and the biological functions of certain lncRNAs remain under considerable debate. Therefore, identification of highly specific and sensitive lncRNAs for the early monitoring of the invasion and metastasis of breast cancer remains an arduous task. An improved understanding of the network of genes and cellular pathways regulated by lncRNAs will aid in improving the understanding of breast cancer pathogenesis, and thus will open novel avenues for breast cancer diagnosis, prognosis and therapy.

\section{References}

1. Torre LA, Bray F, Siegel RL, Ferlay J, Lortet-Tieulent J and Jemal A: Global cancer statistics, 2012. CA Cancer J Clin 65: 87-108, 2015

2. DeSantis C, Ma J, Bryan L and Jemal A: Breast cancer statistics, 2013. CA Cancer J Clin 64: 52-62, 2014

3. Huober J and Thürlimann B: The role of combination chemotherapy in the treatment of patients with metastatic breast cancer. Breast Care (Basel) 4: 367-372, 2009.

4. Ferlay J, Shin HR, Bray F, Forman D, Mathers C and Parkin DM: Estimates of worldwide burden of cancer in 2008: GLOBOCAN 2008. Int J Cancer 127: 2893-2917, 2010.

5. Cardoso F, Harbeck N, Fallowfield L, Kyriakides S and Senkus E; ESMO Guidelines Working Group: Locally recurrent or metastatic breast cancer: ESMO Clinical Practice Guidelines for diagnosis, treatment and follow-up. Ann Oncol 23 (Suppl 7): vii11-vii19, 2012

6. Siegel R, Naishadham D and Jemal A: Cancer statistics, 2013. CA Cancer J Clin 63: 11-30, 2013.

7. Valastyan S and Weinberg RA: Tumor metastasis: Molecular insights and evolving paradigms. Cell 147: 275-292, 2011.

8. Chaffer CL and Weinberg RA: A perspective on cancer cell metastasis. Science 331: 1559-1564, 2011.

9. Zhang J, Tian XJ, Zhang H, Teng Y, Li R, Bai F, Elankumaran S and Xing J: TGF- $\beta$-induced epithelial-to-mesenchymal transition proceeds through stepwise activation of multiple feedback loops. Sci Signal 7: ra91, 2014.

10. Gutschner T and Diederichs S: The hallmarks of cancer: A long non-coding RNA point of view. RNA Biol 9: 703-719, 2012.

11. Djebali S, Davis CA, Merkel A, Dobin A, Lassmann T, Mortazavi A, Tanzer A, Lagarde J, Lin W, Schlesinger F, et al: Landscape of transcription in human cells. Nature 489: 101-108, 2012.

12. Mercer TR, Dinger ME and Mattick JS: Long non-coding RNAs: Insights into functions. Nat Rev Genet 10: 155-159, 2009.

13. van Bakel $\mathrm{H}$ and Hughes TR: Establishing legitimacy and function in the new transcriptome. Brief Funct Genomic Proteomic 8: 424-436, 2009.

14. Perkel JM: Visiting 'noncodarnia'. Biotechniques 54: 301, 303-304, 2013.

15. Fabian MR and Sonenberg N: The mechanics of miRNA-mediated gene silencing: A look under the hood of miRISC. Nat Struct Mol Biol 19: 586-593, 2012.

16. Kong YW, Ferland-McCollough D, Jackson TJ and Bushell M: microRNAs in cancer management. Lancet Oncol 13: e249-e258, 2012

17. Huarte M and Rinn JL: Large non-coding RNAs: Missing links in cancer? Hum Mol Genet 19: R152-R161, 2010.

18. Gibb EA, Brown CJ and Lam WL: The functional role of long non-coding RNA in human carcinomas. Mol Cancer 10: 38, 2011.

19. Prensner JR and Chinnaiyan AM: The emergence of lncRNAs in cancer biology. Cancer Discov 1: 391-407, 2011.

20. Hauptman N and Glavač D: Long non-coding RNA in cancer. Int J Mol Sci 14: 4655-4669, 2013.

21. Wilusz JE, Sunwoo H and Spector DL: Long noncoding RNAs: Functional surprises from the RNA world. Genes Dev 23: 1494-1504, 2009

22. Ernst $\mathrm{C}$ and Morton CC: Identification and function of long non-coding RNA. Front Cell Neurosci 7: 168, 2013.
23. Derrien T, Johnson R, Bussotti G, Tanzer A, Djebali S, Tilgner H, Guernec G, Martin D, Merkel A, Knowles DG, et al: The GENCODE v7 catalog of human long noncoding RNAs: Analysis of their gene structure, evolution, and expression. Genome Res 22: 1775-1789, 2012.

24. Nie L, Wu HJ, Hsu JM, Chang SS, Labaff AM, Li CW, Wang Y, Hsu JL and Hung MC: Long non-coding RNAs: Versatile master regulators of gene expression and crucial players in cancer. Am J Transl Res 4: 127-150, 2012.

25. van Heesch S, van Iterson M, Jacobi J, Boymans S, Essers PB, de Bruijn E, Hao W, MacInnes AW, Cuppen E and Simonis M: Extensive localization of long noncoding RNAs to the cytosol and mono- and polyribosomal complexes. Genome Biol 15: R6, 2014.

26. Wang KC and Chang HY: Molecular mechanisms of long noncoding RNAs. Mol Cell 43: 904-914, 2011

27. Ponting CP, Oliver PL and Reik W: Evolution and functions of long noncoding RNAs. Cell 136: 629-641, 2009.

28. Rinn JL and Chang HY: Genome regulation by long noncoding RNAs. Annu Rev Biochem 81: 145-166, 2012.

29. Guttman M and Rinn JL: Modular regulatory principles of large non-coding RNAs. Nature 482: 339-346, 2012.

30. Mattick JS: The genetic signatures of noncoding RNAs. PLoS Genet 5: e1000459, 2009.

31. Bergmann JH and Spector DL: Long non-coding RNAs: Modulators of nuclear structure and function. Curr Opin Cell Biol 26: 10-18, 2014.

32. Foroni C, Broggini M, Generali D and Damia G: Epithelialmesenchymal transition and breast cancer: Role, molecular mechanisms and clinical impact. Cancer Treat Rev 38: 689-697, 2012.

33. Vanharanta $\mathrm{S}$ and Massagué J: Origins of metastatic traits. Cancer Cell 24: 410-421, 2013.

34. Lamouille S, Subramanyam D, Blelloch R and Derynck R: Regulation of epithelial-mesenchymal and mesenchymal-epithelial transitions by microRNAs. Curr Opin Cell Biol 25: 200-207, 2013.

35. Brabletz T: To differentiate or not-routes towards metastasis. Nat Rev Cancer 12: 425-436, 2012.

36. Chaw SY, Majeed AA, Dalley AJ, Chan A, Stein S and Farah CS: Epithelial to mesenchymal transition (EMT) biomarkers-E-cadherin, beta-catenin, APC and Vimentin-in oral squamous cell carcinogenesis and transformation. Oral Oncol 48: 997-1006, 2012.

37. Marsan M, Van den Eynden G, Limame R, Neven P, Hauspy J, Van Dam PA, Vergote I, Dirix LY, Vermeulen PB and Van Laere SJ: A core invasiveness gene signature reflects epithelial-to-mesenchymal transition but not metastatic potential in breast cancer cell lines and tissue samples. PLoS One 9: e89262, 2014.

38. Jin L, Chen J, Li L, Li C, Chen C and Li S: CRH suppressed TGF $\beta 1$-induced Epithelial-Mesenchymal Transition via induction of E-cadherin in breast cancer cells. Cell Signal 26: 757-765, 2014

39. Gumbiner BM: Regulation of cadherin-mediated adhesion in morphogenesis. Nat Rev Mol Cell Biol 6: 622-634, 2005.

40. Gheldof A and Berx G: Cadherins and epithelial-to-mesenchymal transition. Prog Mol Biol Transl Sci 116: 317-336, 2013.

41. Kalluri R and Weinberg RA: The basics of epithelial-mesenchymal transition. J Clin Invest 119: 1420-1428, 2009.

42. Acloque H, Adams MS, Fishwick K, Bronner-Fraser M and Nieto MA: Epithelial-mesenchymal transitions: The importance of changing cell state in development and disease. J Clin Invest 119: 1438-1449, 2009

43. Oka H, Shiozaki H, Kobayashi K, Inoue M, Tahara H, Kobayashi T, Takatsuka Y, Matsuyoshi N, Hirano S, Takeichi M, et al: Expression of E-cadherin cell adhesion molecules in human breast cancer tissues and its relationship to metastasis. Cancer Res 53: 1696-1701, 1993.

44. Schipper JH, Frixen UH, Behrens J, Unger A, Jahnke K and Birchmeier W: E-cadherin expression in squamous cell carcinomas of head and neck: Inverse correlation with tumor dedifferentiation and lymph node metastasis. Cancer Res 51: 6328-6337, 1991.

45. Derksen PW, Liu X, Saridin F, van der Gulden H, Zevenhoven J, Evers B, van Beijnum JR, Griffioen AW, Vink J, Krimpenfort P, et al: Somatic inactivation of E-cadherin and p53 in mice leads to metastatic lobular mammary carcinoma through induction of anoikis resistance and angiogenesis. Cancer Cell 10: 437-449, 2006 
46. Onder TT, Gupta PB, Mani SA, Yang J, Lander ES and Weinberg RA: Loss of E-cadherin promotes metastasis via multiple downstream transcriptional pathways. Cancer Res 68 : 3645-3654, 2008

47. Mallini P, Lennard T, Kirby J and Meeson A: Epithelial-tomesenchymal transition: What is the impact on breast cancer stem cells and drug resistance. Cancer Treat Rev 40: 341-348, 2014.

48. Chao Y, Wu Q, Acquafondata M, Dhir R and Wells A: Partial mesenchymal to epithelial reverting transition in breast and prostate cancer metastases. Cancer Microenviron 5: 19-28, 2012.

49. Moody SE, Perez D, Pan TC, Sarkisian CJ, Portocarrero CP, Sterner CJ, Notorfrancesco KL, Cardiff RD and Chodosh LA: The transcriptional repressor Snail promotes mammary tumor recurrence. Cancer Cell 8: 197-209, 2005.

50. De Craene B and Berx G: Regulatory networks defining EMT during cancer initiation and progression. Nat Rev Cancer 13: 97-110, 2013

51. Lin T, Ponn A, Hu X, Law BK and Lu J: Requirement of the histone demethylase LSD1 in Snail-mediated transcriptional repression during epithelial-mesenchymal transition. Oncogene 29: 4896-4904, 2010

52. Tong ZT, Cai MF, Wang XG, Kong LL, Mai SJ, Liu YH, Zhang HB, Liao YJ, Zheng F, Zhu W, et al: EZH2 supports nasopharyngeal carcinoma cell aggressiveness by forming a co-repressor complex with HDAC1/HDAC2 and Snail to inhibit E-cadherin. Oncogene 31: 583-594, 2012.

53. Herranz N, Pasini D, Díaz VM, Francí C, Gutierrez A, Dave N, Escrivà M, Hernandez-Muñoz I, Di Croce L, Helin K, et al: Polycomb complex 2 is required for E-cadherin repression by the Snail1 transcription factor. Mol Cell Biol 28: 4772-4781, 2008.

54. Dong C, Wu Y, Wang Y, Wang C, Kang T, Rychahou PG, Chi YI, Evers BM and Zhou BP: Interaction with Suv39H1 is critical for Snail-mediated E-cadherin repression in breast cancer. Oncogene 32: 1351-1362, 2013.

55. Dong C, Wu Y, Yao J, Wang Y, Yu Y, Rychahou PG, Evers BM and Zhou BP: G9a interacts with Snail and is critical for Snail-mediated E-cadherin repression in human breast cancer. J Clin Invest 122: 1469-1486, 2012.

56. Polyak K and Weinberg RA: Transitions between epithelial and mesenchymal states: Acquisition of malignant and stem cell traits. Nat Rev Cancer 9: 265-273, 2009.

57. Yang J and Weinberg RA: Epithelial-mesenchymal transition: At the crossroads of development and tumor metastasis. Dev Cell 14: 818-829, 2008

58. Dubrovska A, Kim S, Salamone RJ, Walker JR, Maira SM, García-Echeverría C, Schultz PG and Reddy VA: The role of PTEN/Akt/PI3K signaling in the maintenance and viability of prostate cancer stem-like cell populations. Proc Natl Acad Sci USA 106: 268-273, 2009.

59. Padua D and Massagué J: Roles of TGFbeta in metastasis. Cell Res 19: 89-102, 2009.

60. Zhou BP and Hung MC: Wnt, hedgehog and snail: Sister pathways that control by GSK-3beta and beta-Trcp in the regulation of metastasis. Cell Cycle 4: 772-776, 2005

61. GuoF,Parker Kerrigan BC, Yang D, Hu L, ShmulevichI, Sood AK, Xue F and Zhang W: Post-transcriptional regulatory network of epithelial-to-mesenchymal and mesenchymal-to-epithelial transitions. J Hematol Oncol 7: 19, 2014.

62. Ceppi P and Peter ME: MicroRNAs regulate both epithelial-to-mesenchymal transition and cancer stem cells. Oncogene 33: 269-278, 2014.

63. Dumont $\mathrm{N}$ and Tlsty TD: Reflections on miR-ing effects in metastasis. Cancer Cell 16: 3-4, 2009.

64. Rinn JL, Kertesz M, Wang JK, Squazzo SL, Xu X, Brugmann SA, Goodnough LH, Helms JA, Farnham PJ, Segal E and Chang HY: Functional demarcation of active and silent chromatin domains in human HOX loci by noncoding RNAs. Cell 129: 1311-1323, 2007.

65. Gupta RA, Shah N, Wang KC, Kim J, Horlings HM, Wong DJ, Tsai MC, Hung T, Argani P, Rinn JL, et al: Long non-coding RNA HOTAIR reprograms chromatin state to promote cancer metastasis. Nature 464: 1071-1076, 2010.

66. Kleer CG, Cao Q, Varambally S, Shen R, Ota I, Tomlins SA, Ghosh D, Sewalt RG, Otte AP, Hayes DF, et al: EZH2 is a marker of aggressive breast cancer and promotes neoplastic transformation of breast epithelial cells. Proc Natl Acad Sci USA 100: 11606-11611, 2003
67. Chisholm KM, Wan Y, Li R, Montgomery KD, Chang HY and West RB: Detection of long non-coding RNA in archival tissue: Correlation with polycomb protein expression in primary and metastatic breast carcinoma. PLoS One 7: e47998, 2012.

68. Padua Alves C, Fonseca AS, Muys BR, de Barros E Lima Bueno R, Bürger MC, de Souza JE, Valente V, Zago MA and Silva WA Jr: Brief report: The lincRNA Hotair is required for epithelial-to-mesenchymal transition and stemness maintenance of cancer cell lines. Stem Cells 31: 2827-2832, 2013.

69. Zhang H, Cai K, Wang J, Wang X, Cheng K, Shi F, Jiang L, Zhang Y and Dou J: MiR-7, inhibited indirectly by lincRNA HOTAIR, directly inhibits SETDB1 and reverses the EMT of breast cancer stem cells by downregulating the STAT3 pathway. Stem Cells 32: 2858-2868, 2014.

70. Li JT, Wang LF, Zhao YL, Yang T, Li W, Zhao J, Yu F, Wang L, Meng YL, Liu NN, et al: Nuclear factor of activated T cells 5 maintained by Hotair suppression of miR-568 upregulates S100 calcium binding protein A4 to promote breast cancer metastasis. Breast Cancer Res 16: 454, 2014.

71. Gokmen-Polar Y, Vladislav IT, Neelamraju Y, Janga SC and Badve S: Prognostic impact of HOTAIR expression is restricted to ER-negative breast cancers. Sci Rep 5: 8765, 2015.

72. Sorensen KP, Thomassen M, Tan Q, Bak M, Cold S, Burton M, Larsen MJ and Kruse TA: Long non-coding RNA HOTAIR is an independent prognostic marker of metastasis in estrogen receptor-positive primary breast cancer. Breast Cancer Res Treat 142: 529-536, 2013

73. Bhan A, Hussain I, Ansari KI, Kasiri S, Bashyal A and Mandal SS: Antisense transcript long noncoding RNA (lncRNA) HOTAIR is transcriptionally induced by estradiol. J Mol Biol 425: 3707-3722, 2013.

74. Bhan A, Hussain I, Ansari KI, Bobzean SA, Perrotti LI and Mandal SS: Bisphenol-A and diethylstilbestrol exposure induces the expression of breast cancer associated long noncoding RNA HOTAIR in vitro and in vivo. J Steroid Biochem Mol Biol 141: 160-170, 2014.

75. Tao S, He H and Chen Q: Estradiol induces HOTAIR levels via GPER-mediated miR-148a inhibition in breast cancer. J Transl Med 13: 131, 2015.

76. Bartolomei MS,Zemel S and Tilghman SM: Parental imprinting of the mouse H19 gene. Nature 351: 153-155, 1991.

77. Gabory A, Jammes H and Dandolo L: The H19 locus: Role of an imprinted non-coding RNA in growth and development. Bioessays 32: 473-480, 2010.

78. Brannan CI, Dees EC, Ingram RS and Tilghman SM: The product of the H19 gene may function as an RNA. Mol Cell Biol 10: 28-36, 1990

79. Giannoukakis N, Deal C, Paquette J, Goodyer CG and Polychronakos C: Parental genomic imprinting of the human IGF2 gene. Nat Genet 4: 98-101, 1993.

80. Soejima $\mathrm{H}$ and Higashimoto K: Epigenetic and genetic alterations of the imprinting disorder Beckwith-Wiedemann syndrome and related disorders. J Hum Genet 58: 402-409, 2013.

81. Ma C, Nong K, Zhu H, Wang W, Huang X, Yuan Z and Ai K: H19 promotes pancreatic cancer metastasis by derepressing let-7's suppression on its target HMGA2-mediated EMT. Tumour Biol 35: 9163-9169, 2014

82. Luo M, Li Z, Wang W, Zeng Y, Liu Z and Qiu J: Long non-coding RNA H19 increases bladder cancer metastasis by associating with EZH2 and inhibiting E-cadherin expression. Cancer Lett 333: 213-221, 2013.

83. Tsang WP, Ng EK, Ng SS, Jin H, Yu J, Sung JJ and Kwok TT: Oncofetal H19-derived miR-675 regulates tumor suppressor RB in human colorectal cancer. Carcinogenesis 31: 350-358, 2010.

84. Li H, Yu B, Li J, Su L, Yan M, Zhu Z and Liu B: Overexpression of lncRNA H19 enhances carcinogenesis and metastasis of gastric cancer. Oncotarget 5: 2318-2329, 2014.

85. Lottin S, Adriaenssens E, Dupressoir T, Berteaux N, Montpellier C, Coll J, Dugimont T and Curgy JJ: Overexpression of an ectopic $\mathrm{H} 19$ gene enhances the tumorigenic properties of breast cancer cells. Carcinogenesis 23: 1885-1895, 2002.

86. Adriaenssens E, Lottin S, Berteaux N, Hornez L, Fauquette W, Fafeur V, Peyrat JP, Le Bourhis X, Hondermarck H, Coll J, et al: Cross-talk between mesenchyme and epithelium increases H19 gene expression during scattering and morphogenesis of epithelial cells. Exp Cell Res 275: 215-229, 2002.

87. Berteaux N, Lottin S, Monte D, Pinte S, Quatannens B, Coll J, Hondermarck H, Curgy JJ, Dugimont T and Adriaenssens E: H19 mRNA-like noncoding RNA promotes breast cancer cell proliferation through positive control by E2F1. J Biol Chem 280: 29625-29636, 2005. 
88. Matouk IJ, Raveh E, Abu-lail R, Mezan S, Gilo M, Gershtain E, Birman T, Gallula J, Schneider T, Barkali M, et al: Oncofetal H19 RNA promotes tumor metastasis. Biochim Biophys Acta 1843: 1414-1426, 2014.

89. Xue G, Restuccia DF, Lan Q, Hynx D, Dirnhofer S, Hess D, Rüegg $\mathrm{C}$ and Hemmings BA: Akt/PKB-mediated phosphorylation of Twist 1 promotes tumor metastasis via mediating cross-talk between PI3K/Akt and TGF-beta signaling axes. Cancer discov 2: 248-259, 2012

90. Vennin C, Spruyt N, Dahmani F, Julien S, Bertucci F, Finetti P, Chassat T, Bourette RP, Le Bourhis X and Adriaenssens E: H19 non coding RNA-derived miR-675 enhances tumorigenesis and metastasis of breast cancer cells by downregulating c-Cbl and Cbl-b. Oncotarget 6: 29209-29223, 2015.

91. Ji P, Diederichs S, Wang W, Böing S, Metzger R, Schneider PM, Tidow N, Brandt B, Buerger H, Bulk E, et al: MALAT-1, a novel noncoding RNA and thymosin beta4 predict metastasis and survival in early-stage non-small cell lung cancer. Oncogene 22 8031-8041, 2003.

92. Jiao F, Hu H, Han T, Yuan C, Wang L, Jin Z, Guo Z and Wang L: Long noncoding RNA MALAT-1 enhances stem cell-like phenotypes in pancreatic cancer cells. Int J Mol Sci 16: 6677-6693, 2015

93.Lai MC, Yang Z, Zhou L, Zhu QQ, Xie HY, Zhang F, Wu LM, Chen LM and Zheng SS: Long non-coding RNA MALAT-1 overexpression predicts tumor recurrence of hepatocellular carcinoma after liver transplantation. Med Oncol 29: 1810-1816, 2012.

94.Zhang ZJ, Tong YQ, Wang JJ, Yang C, Zhou GH, Li YH, Xie PL, Hu JY and Li GC: Spaceflight alters the gene expression profile of cervical cancer cells. Chin J Cancer 30: 842-852, 2011.

95.Xu C, Yang M, Tian J, Wang X and Li Z: MALAT-1: A long non-coding RNA and its important 3 ' end functional motif in colorectal cancer metastasis. Int J Oncol 39: 169-175, 2011.

96. Ying L, Chen Q, Wang Y, Zhou Z, Huang Y and Qiu F Upregulated MALAT-1 contributes to bladder cancer cell migration by inducing epithelial-to-mesenchymal transition. Mol Biosyst 8: 2289-2294, 2012.

97. Zhao Z, Chen C, Liu Y and Wu C: 17ß-Estradiol treatment inhibits breast cell proliferation, migration and invasion by decreasing MALAT-1 RNA level. Biochem Biophys Res Commun 445 388-393, 2014.

98. Hanahan D and Weinberg RA: Hallmarks of cancer: The next generation. Cell 144: 646-674, 2011.

99. Tano K and Akimitsu N: Long non-coding RNAs in cancer progression. Front Genet 3: 219, 2012.

100. Xu S, Sui S, Zhang J, Bai N, Shi Q, Zhang G, Gao S, You Z, Zhan C, Liu F and Pang D: Downregulation of long noncoding RNA MALAT1 induces epithelial-to-mesenchymal transition via the PI3K-AKT pathway in breast cancer. Int J Clin Exp Pathol 8: 4881-4891, 2015.

101. Silva JM, Boczek N, Berres MW, Ma X and Smith DI: LSINCT5 is over expressed in breast and ovarian cancer and affects cellular proliferation. RNA Biol 8: 496-505, 2011.

102. Silva JM, Perez DS, Pritchett JR, Halling ML, Tang H and Smith DI: Identification of long stress-induced non-coding transcripts that have altered expression in cancer. Genomics 95 355-362, 2010.

103.Hassan S, Buchanan M, Jahan K, Aguilar-Mahecha A, Gaboury L, Muller WJ, Alsawafi Y, Mourskaia AA, Siegel PM, Salvucci $\mathrm{O}$ and Basik M: CXCR4 peptide antagonist inhibits primary breast tumor growth, metastasis and enhances the efficacy of anti-VEGF treatment or docetaxel in a transgenic mouse model. Int J Cancer 129: 225-232, 2011.

104. Sobolik T, Su YJ, Wells S, Ayers GD, Cook RS and Richmond A: CXCR4 drives the metastatic phenotype in breast cancer through induction of CXCR 2 and activation of MEK and PI3K pathways. Mol Biol Cell 25: 566-582, 2014.

105. Yang P, Liang SX, Huang WH, Zhang HW, Li XL, Xie LH, Du CW and Zhang GJ: Aberrant expression of CXCR4 significantly contributes to metastasis and predicts poor clinical outcome in breast cancer. Curr Mol Med 14: 174-184, 2014.

106. Loewer S, Cabili MN, Guttman M, Loh YH, Thomas K, Park IH, Garber M, Curran M, Onder T, Agarwal S, et al: Large intergenic non-coding RNA-RoR modulates reprogramming of human induced pluripotent stem cells. Nat Genet 42: 1113-1117, 2010

107.Zhang A, Zhou N, Huang J, Liu Q, Fukuda K, Ma D, Lu Z, Bai C, Watabe $\mathrm{K}$ and Mo YY: The human long non-coding RNA-RoR is a p53 repressor in response to DNA damage. Cell Res 23: 340-350, 2013
108. Zhang Y, Xia J, Li Q, Yao Y, Eades G, Gernapudi R, Duru N, Kensler TW and Zhou Q: NRF2/long noncoding RNA ROR signaling regulates mammary stem cell expansion and protects against estrogen genotoxicity. J Biol Chem 289: 31310-31318, 2014.

109. Wang Y, Xu Z, Jiang J, Xu C, Kang J, Xiao L, Wu M, Xiong J, Guo $\mathrm{X}$ and Liu H: Endogenous miRNA sponge lincRNA-RoR regulates Oct4, Nanog, and Sox 2 in human embryonic stem cell self-renewal. Dev Cell 25: 69-80, 2013.

110. Yin X, Zhang BH, Zheng SS, Gao DM, Qiu SJ, Wu WZ and Ren ZG: Coexpression of gene Oct4 and Nanog initiates stem cell characteristics in hepatocellular carcinoma and promotes epithelial-mesenchymal transition through activation of Stat3/Snail signaling. J Hematol Oncol 8: 23, 2015.

111. Liu L, Zhang J, Fang C, Zhang Z, Feng Y and Xi X: OCT4 mediates FSH-induced epithelial-mesenchymal transition and invasion through the ERK1/2 signaling pathway in epithelial ovarian cancer. Biochem Biophys Res Commun 461: 525-532, 2015.

112. Hu J, Guo H, Li H, Liu Y, Liu J, Chen L, Zhang J and Zhang N: MiR-145 regulates epithelial to mesenchymal transition of breast cancer cells by targeting Oct4. PLoS One 7: e45965, 2012.

113. Eades G, Wolfson B, Zhang Y, Li Q, Yao Y and Zhou Q: lincRNA-RoR and miR-145 regulate invasion in triple-negative breast cancer via targeting ARF6. Mol Cancer Res 13: 330-338, 2015.

114. Hashimoto S, Onodera Y, Hashimoto A, Tanaka M,Hamaguchi M, Yamada A and Sabe H: Requirement for Arf6 in breast cancer invasive activities. Proc Natl Acad Sci USA 101: 6647-6652, 2004.

115. Sabe H, Hashimoto S, Morishige M, Ogawa E, Hashimoto A, Nam JM, Miura K, Yano H and Onodera Y: The EGFR-GEP100Arf6-AMAP1 signaling pathway specific to breast cancer invasion and metastasis. Traffic 10: 982-993, 2009.

116. Hou P, Zhao Y, Li Z, Yao R, Ma M, Gao Y, Zhao L, Zhang Y, Huang B and Lu J: LincRNA-ROR induces epithelial-to-mesenchymal transition and contributes to breast cancer tumorigenesis and metastasis. Cell Death Dis 5: e1287, 2014.

117. Chen YM, Liu Y, Wei HY, Lv KZ and Fu P: Linc-ROR induces epithelial-mesenchymal transition and contributes to drug resistance and invasion of breast cancer cells. Tumour Biol 37: 10861-10870, 2016

118. Orom UA, Derrien T, Beringer M, Gumireddy K, Gardini A, Bussotti G, Lai F, Zytnicki M, Notredame C, Huang Q, et al: Long noncoding RNAs with enhancer-like function in human cells. Cell 143: 46-58, 2010.

119. Gumireddy K, Li A, Yan J, Setoyama T, Johannes GJ, Orom UA, Tchou J, Liu Q, Zhang L, Speicher DW, et al: Identification of a long non-coding RNA-associated RNP complex regulating metastasis at the translational step. EMBO J 32: 2672-2684, 2013.

120. Hansji H, Leung EY, Baguley BC, Finlay GJ and AskarianAmiri ME: Keeping abreast with long non-coding RNAs in mammary gland development and breast cancer. Front Genet 5 : 379, 2014.

121. Watson JB and Sutcliffe JG: Primate brain-specific cytoplasmic transcript of the Alu repeat family. Mol Cell Biol 7: 3324-3327, 1987.

122. Tiedge H, Chen W and Brosius J: Primary structure, neural-specific expression, and dendritic location of human BC200 RNA. J Neurosci 13: 2382-2390, 1993.

123. Chen W, Böcker W, Brosius J and Tiedge H: Expression of neural BC200 RNA in human tumours. J Pathol 183: 345-351, 1997.

124. Iacoangeli A, Lin Y, Morley EJ, Muslimov IA, Bianchi R, Reilly J, Weedon J, Diallo R, Böcker W and Tiedge H: BC200 RNA in invasive and preinvasive breast cancer. Carcinogenesis 25: 2125-2133, 2004.

125. De Leeneer K and Claes K: Non Coding RNA Molecules as Potential Biomarkers in Breast Cancer. Adv Exp Med Biol 867: 263-275, 2015

126. Yuan JH, Yang F, Wang F, Ma JZ, Guo YJ, Tao QF, Liu F, Pan W, Wang TT, Zhou CC, et al: A long noncoding RNA activated by TGF- $\beta$ promotes the invasion-metastasis cascade in hepatocellular carcinoma. Cancer Cell 25: 666-681, 2014.

127. Li W and Kang Y: A new Lnc in metastasis: Long noncoding RNA mediates the prometastatic functions of TGF- $\beta$. Cancer Cell 25: 557-559, 2014

128. Iguchi T, Uchi R, Nambara S, Saito T, Komatsu H, Hirata H, Ueda M, Sakimura S, Takano Y, Kurashige J, et al: A long noncoding RNA, IncRNA-ATB, is involved in the progression and prognosis of colorectal cancer. Anticancer Res 35: 1385-1388, 2015 . 
129. Saito T, Kurashige J, Nambara S, Komatsu H, Hirata H, Ueda M, Sakimura S, Uchi R, Takano Y, Shinden Y, et al: A long non-coding RNA activated by transforming growth factor-beta is an independent prognostic marker of gastric cancer. Ann Surg Oncol 22 (Suppl 3): 915-922, 2015.

130.Kang Y, Siegel PM, Shu W, Drobnjak M, Kakonen SM, Cordón-Cardo C, Guise TA and Massagué J: A multigenic program mediating breast cancer metastasis to bone. Cancer Cell 3: 537-549, 2003.

131. Shi SJ, Wang LJ, Yu B, Li YH, Jin Y and Bai XZ: LncRNA-ATB promotes trastuzumab resistance and invasion-metastasis cascade in breast cancer. Oncotarget 6: 11652-11663, 2015.

132. Meijer D, van Agthoven T, Bosma PT, Nooter K and Dorssers LC: Functional screen for genes responsible for tamoxifen resistance in human breast cancer cells. Mol Cancer Res 4: 379-386, 2006

133. Godinho MF, Sieuwerts AM, Look MP, Meijer D, Foekens JA, Dorssers LC and van Agthoven T: Relevance of BCAR4 in tamoxifen resistance and tumour aggressiveness of human breast cancer. Br J Cancer 103: 1284-1291, 2010.

134. Godinho M, Meijer D, Setyono-Han B, Dorssers LC and van Agthoven T: Characterization of BCAR4, a novel oncogene causing endocrine resistance in human breast cancer cells. J Cell Physiol 226: 1741-1749, 2011.

135. Xing Z, Lin A, Li C, Liang K, Wang S, Liu Y, Park PK, Qin L, Wei Y, Hawke DH, et al: lncRNA directs cooperative epigenetic regulation downstream of chemokine signals. Cell 159: 1110-1125, 2014.

136. Xing Z, Lin C and Yang L: Unraveling the therapeutic potential of the LncRNA-dependent noncanonical Hedgehog pathway in cancer. Mol Cell Oncol 2: e998900, 2015.

137. Xing Z, Park PK, Lin C and Yang L: LncRNA BCAR4 wires up signaling transduction in breast cancer. RNA Biol 12: 681-689, 2015.

138. Richards EJ, Zhang G, Li ZP, Permuth-Wey J, Challa S, Li Y, Kong W, Dan S, Bui MM, Coppola D, et al: Long non-coding RNAs (LncRNA) regulated by transforming growth factor (TGF) $\beta$ : LncRNA-hit-mediated TGF $\beta$-induced epithelial to mesenchymal transition in mammary epithelia. J Biol Chem 290: 6857-6867, 2015.

139. Liu B, Sun L, Liu Q, Gong C, Yao Y, Lv X, Lin L, Yao H, Su F, Li D, et al: A cytoplasmic NF- $\mathrm{B}$ interacting long noncoding RNA blocks I $\kappa$ phosphorylation and suppresses breast cancer metastasis. Cancer Cell 27: 370-381, 2015.
140. Pandey GK, Mitra S, Subhash S, Hertwig F, Kanduri M, Mishra K, Fransson S, Ganeshram A, Mondal T, Bandaru S, et al: The risk-associated long noncoding RNA NBAT-1 controls neuroblastoma progression by regulating cell proliferation and neuronal differentiation. Cancer Cell 26: 722-737, 2014

141.Pandey GK and Kanduri C: Fighting Neuroblastomas with NBAT1. Oncoscience 2: 79-80, 2015.

142. Hu P, Chu J, Wu Y, Sun L, Lv X, Zhu Y, Li J, Guo Q, Gong C, Liu B and Su S: NBAT1 suppresses breast cancer metastasis by regulating DKK1 via PRC2. Oncotarget 6: 32410-32425, 2015.

143. Cowling VH, D'Cruz CM, Chodosh LA and Cole MD: c-Myc transforms human mammary epithelial cells through repression of the Wnt inhibitors DKK1 and SFRP1. Mol Cell Biol 27: 5135-5146, 2007.

144. Sato N, Yamabuki T, Takano A, Koinuma J, Aragaki M, Masuda K, Ishikawa N, Kohno N, Ito H, Miyamoto M, et al: Wnt inhibitor Dickkopf-1 as a target for passive cancer immunotherapy. Cancer Res 70: 5326-5336, 2010.

145. Xu WH, Liu ZB, Yang C, Qin W and Shao ZM: Expression of dickkopf-1 and beta-catenin related to the prognosis of breast cancer patients with triple negative phenotype. PLoS One 7: e37624, 2012.

146. Hu P, Chu J, Wu Y, Sun L, Lv X, Zhu Y, Li J, Guo Q, Gong C, Liu B and Su S: NBAT1 suppresses breast cancer metastasis by regulating DKK1 via PRC2. Oncotarget 6: 32410-32425, 2015.

147. Foulds CE, Tsimelzon A, Long W, Le A, Tsai SY, Tsai MJ and O'Malley BW: Research resource: Expression profiling reveals unexpected targets and functions of the human steroid receptor RNA activator (SRA) gene. Mol Endocrinol 24: 1090-1105, 2010.

148. Li H, Zhu L, Xu L, Qin K, Liu C, Yu Y, Su D, Wu K and Sheng Y: Long noncoding RNA linc00617 exhibits oncogenic activity in breast cancer. Mol Carcinog 56: 3-17, 2017.

149. Shi Y, Lu J, Zhou J, Tan X, He Y, Ding J, Tian Y, Wang L and Wang K: Long non-coding RNA Loc554202 regulates proliferation and migration in breast cancer cells. Biochem Biophys Res Commun 446: 448-453, 2014.

150. He K and Wang P: Unregulated long non-coding RNA-AK058003 promotes the proliferation, invasion and metastasis of breast cancer by regulating the expression levels of the $\gamma$-synuclein gene. Exp Ther Med 9: 1727-1732, 2015. 